\title{
Innovation project value assessment methodology for high-tech enterprises
}

\author{
M.A. Kossukhina ${ }^{1, *}$, and V.I. Fomin ${ }^{1}$ \\ ${ }^{1}$ St. Petersburg State Electrotechnical University “LETI”, St. Petersburg, Russia
}

\begin{abstract}
In the current economic conditions, the innovation project value assessment is a driving force of innovation system development of high-tech enterprises. Innovation projects value assessment is a crucial determinant of technologically advanced industrial enterprises competitiveness in the world market. Therefore it is important to identify the factors that influence on selection of innovation project value assessment methodology for high-tech enterprises. The aim of this paper is to select the innovation project value assessment methodology for high-tech enterprises, that would satisfy their features and to offer the approaches to innovation project value assessment in case of unsuitability of reviewed methodologies. The analytic hierarchy process and fuzzy inference method is used as methods of decisionmaking in this paper.
\end{abstract}

\section{Introduction}

The founder of classical theory of innovation J. Schumpeter pointed out that innovations are not only the production and distribution of new products and services but also application of new production technologies, control of new sales markets as well as creating new organization solutions in economy $[1,4,5,6,8]$. Innovation activities include all scientific, technological, organisational, financial and commercial steps, which actually lead, or are intended to lead, to the implementation of innovations. According to [2, 10-17] it can be stated that every high- tech enterprise is an innovative company; however, not every innovative company is a high-tech one.

Considering the differences between the high-tech enterprises and innovative companies, it is necessary to outline whether the high-tech enterprises are producers/creators of advanced technologies or rather a users, commonly applying such technologies. From our point of view , a "fusion" approach should be used in this case, as high- tech enterprises usually produces advanced technologies, so that it could be used in their products and (or) services. Normally high- tech enterprises have their own R\&D units that produce advanced technologies. In this article, we offer to call them "innovation projects".

Nowadays, innovation projects value assessment is a crucial determinant of technologically advanced industrial enterprises competitiveness in the world market. Therefore, it is important to identify the factors that influence on selection of innovation project value assessment methodology for high-tech enterprises.

\section{The review of innovation project value assessment approaches}

As innovation projects are being considered as business units of high-tech enterprises, their key features should be outlined. The most important attributes of innovation projects could be divided into four groups as following:

- financial features: total size of the financial expenses for R\&D (capital expenses and investment risk);

- team features: flexibility of organization structures, close scientific and technical partnership relations, team work potential, ability to share, use and collect, knowledge;

- means features: fast diffusion of technological innovations, the volume and diversity of collected and processed information, knowledge and unique competences of personnel;

- Idea features. High creativity entrepreneurship, science demand and agility, fast devaluation of the prepared and applied technologies, communication supported with modern IT.

The innovative project, as well as other business functions, requires special tools: the rules, scope, and budget constraints. Let us assume that approaches, which are used to measure business projects value, are common to innovation projects value assessment. Therefore, we offer to consider them taking into account the innovation project features.

Income approach - a set of methods for assessing the valuation of the object, based on the determination of the expected revenue from the object use. There are several variations of the income approach: direct capitalization method, the method of discounted cash flow, and gross

\footnotetext{
*Corresponding author: masha.kossukhina@mail.ru
} 
income multiplier method [5]. Using the income approach has the following disadvantages: this approach requires a subjective allocation of cash flows, the relevant information that is necessary for the calculations, is not always available from internal reporting.

Comparative approach is a set of methods to assess the valuation of the object, based on a comparison of the object with the objects of evaluation - evaluation of analogues of the object, for which there is information on prices. The main disadvantage of this approach is impossibility of application in case of inadequate data availability.

The cost approach - a set of methods for assessing the valuation of the object, based on the determination of costs necessary for the reproduction or replacement of object of evaluation, taking into account wear and tear and obsolescence. The cost approach views the business as a set of assets and liabilities that are used as building blocks to construct the picture of business value. This approach does not capture the cash flow generating ability of the assets or business and cost and value may have large discrepancy.

All of approaches, that we have considered, except comparative, are based on quantitative methods of evaluation, so they are not taking into consideration qualitative characteristics.

It should be noted that the method of estimating the value of the high-tech enterprise innovation project for more accurate assessment should be based on two groups of scales: qualitative and quantitative. Some researchers, however, considering only quantitative metric [18, 19], because of its simplicity to analyze using statistical methods. Other researchers assert the importance of the qualitative approach in measuring the value of innovation projects $[11,14,15]$, as it allows measuring the innovative project value considering its qualitative characteristics.

From our point of view, there is a need to mix quantitative and qualitative approaches to fully assess the value of innovation project.

This article discusses the qualitative modeling method, which allows to transform quantitative values into qualitative, combine them with the values of quality scales method and fuzzy linguistic modeling. Fuzzy modeling suggests the development of qualitative model based on linguistic descriptions. Quantitative data processing can also be performed using fuzzy modeling.

\section{Innovation project value assessment methodology}

In this paper, we are using a special expansion pack Fuzzy Logic Tools in MatLab environment to simulate the process of innovative projects valuation. It is necessary to build a model, which automatically determines the innovation performance value in the output in interactive mode. It is also required to take into account qualitative variables according to the algorithm, with the usage of the graphic editing tools and visualization.

The substantive interpretation involves the selection and specification of the input and output variables corresponding the fuzzy inference system. In this case, the model is supposed to use six input variables and one output. The type of defined system will be outputted on the Mamdani algorithm, so we are going to use min function as activation function. As logical connective "And" is used in all rules in the knowledgebase, then operation min-conjunction is used as the aggregation method. Center of gravity is used as a defuzzification method.

The fuzzy inference system is shown in Figure 1. It is based on the following variables:

- the novelty of innovation projects;

- the quality of the innovation environment;

- high-tech enterprises income from researches;

- the number of license obtained;

- Skolkovo grants

- the number of IPO;

- the innovation project performance.

The function plot is done for every variable of the fuzzy interference model using the editor of membership functions. Membership functions plots of linguistic variables and their descriptions are shown in Figures 2-4. For all of these terms we will use the triangular function trimf. This function uses three parameters a, b, c, take arbitrary real values and ordered $\mathrm{a} \leq \mathrm{b} \leq \mathrm{c}$ attitude.

In the fuzzy inference systems, linguistic variables have different terms for each variable. As a term of the plurality of input variable «the quality of the innovation environment» will use the set $\mathrm{T} 1=\{$ "low", "medium", "high" $\}$, to low term we define the parameters of [-1 -0.6 $0.2]$ to medium term we define the parameters [ $\left[\begin{array}{ll}0.2 & 0.4\end{array}\right.$ $0.6]$ to high term we define the parameters [ 0.60 .81$]$.

As the term sets of the output variable "Innovation project performance», we will use a set $\mathrm{T} 7=\{$ "mfl", "mf2", "mf3"\}. Fig. 4 shows the membership function of the linguistic variable terms ("low", "medium", "high").

The GUI of rules editor after setting the rule base is shown in Figure 5.

The evaluation of mutual values of linguistic variables in the results of the fuzzy inference system shows for example that combination of average values of: high-tech enterprises income from researches, license obtained, Skolkovo grants and IPO with the low value of innovation environment quality, lead to an average value of innovation project performance.

In contrast to investment projects, innovative projects of high tech enterprises is characterized by specific risks and uncertainties arising from technical and market innovation novelty. Therefore, there is a need for new approaches to assess the effectiveness of such projects. Innovation project value assessment methodology based on fuzzy logic approach, which is offered in this paper, could be used to evaluate innovation project effectiveness as a first-step methodology because of its simplicity. 


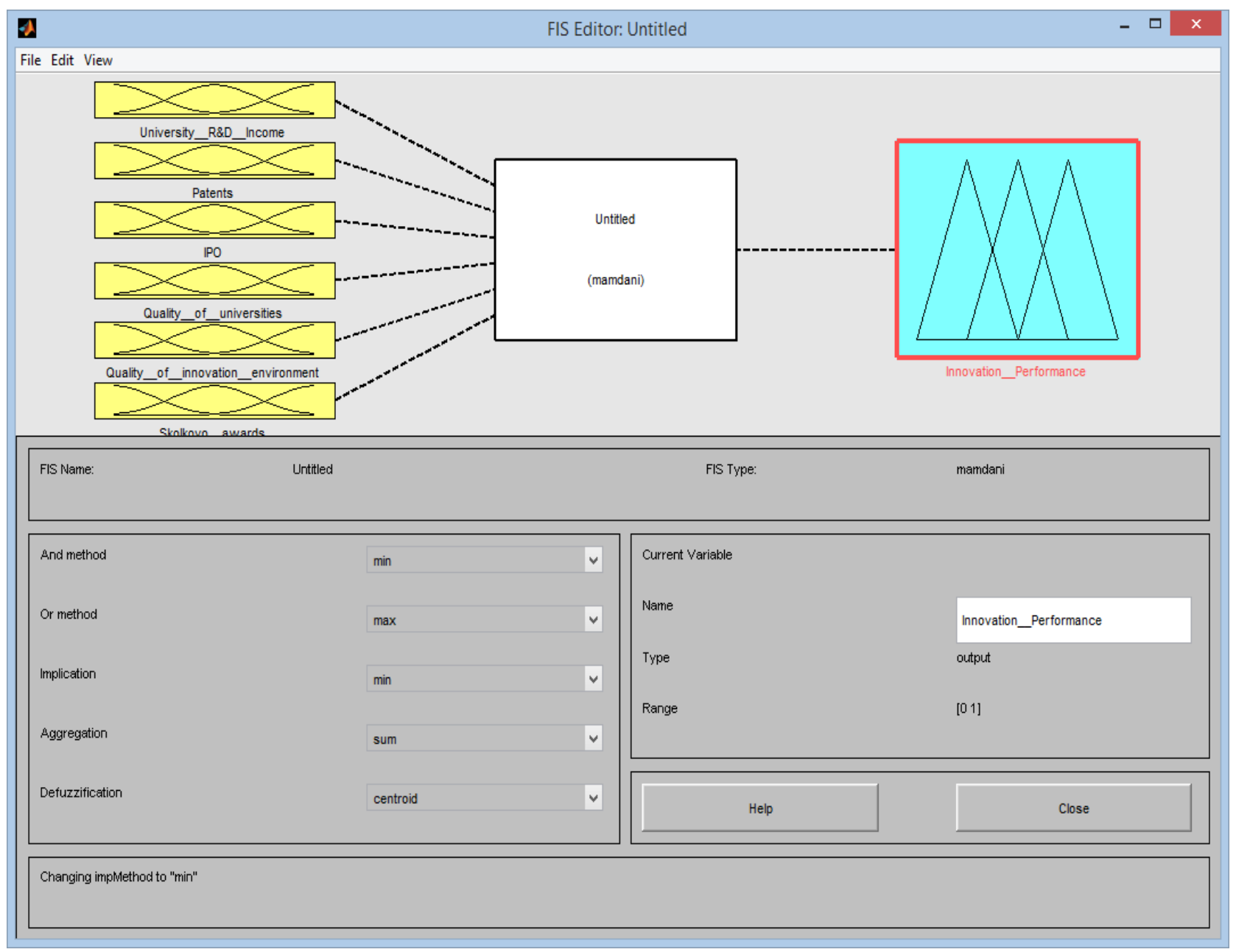

Fig. 1. Graphical user interface of FIS editor after determining input and output variables of the fuzzy inference system.

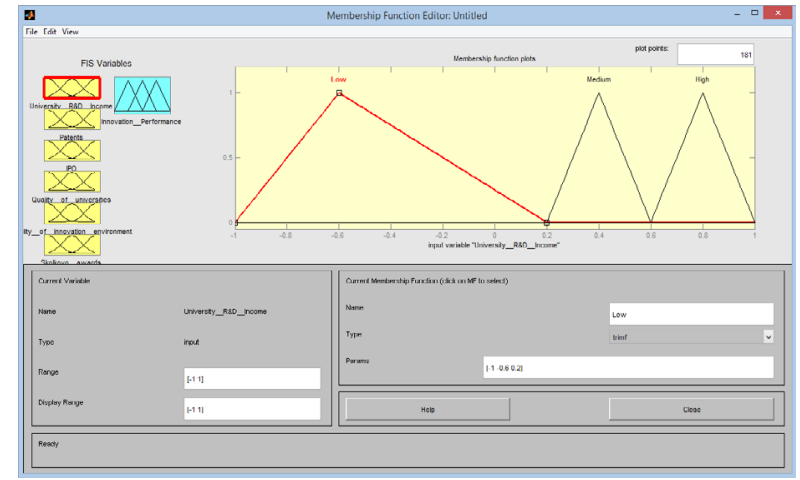

Fig. 2. The GUI of membership functions editor for the input variable " high-tech enterprises income from researches".

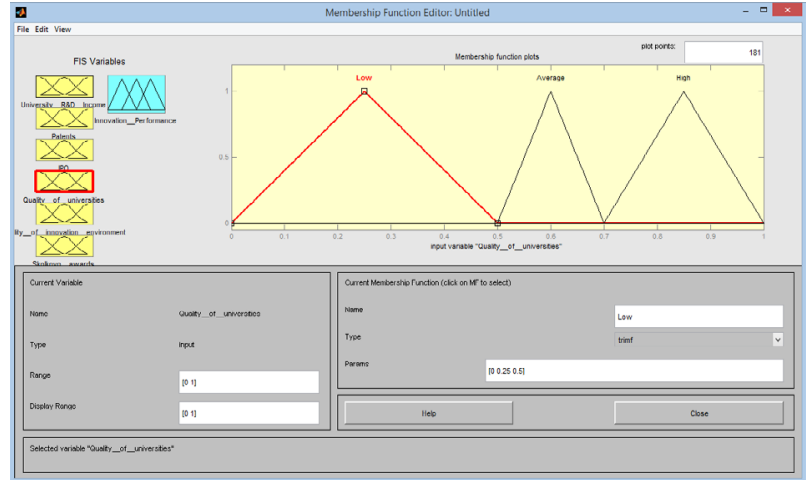

Fig. 3. The GUI of membership functions editor for the input variable "the quality of the innovation environment. 


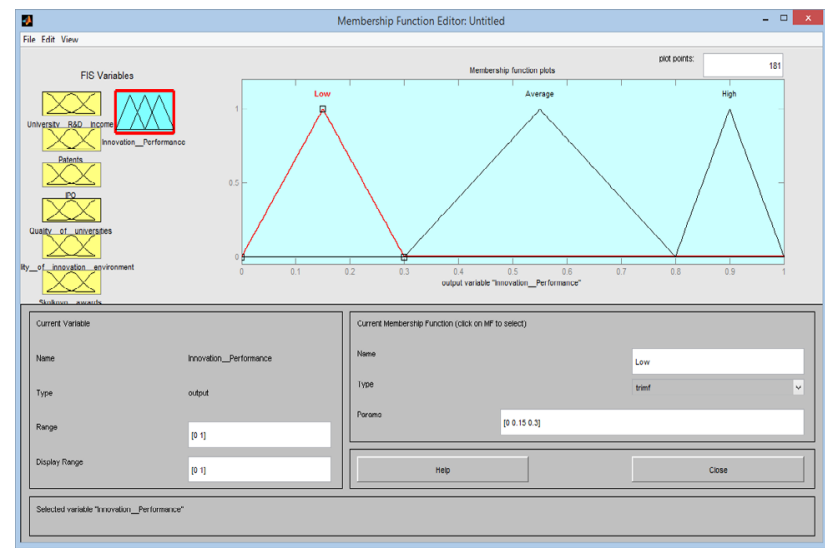

Fig. 4. The GUI of membership functions editor for the output variable "Innovation project perfprmance".

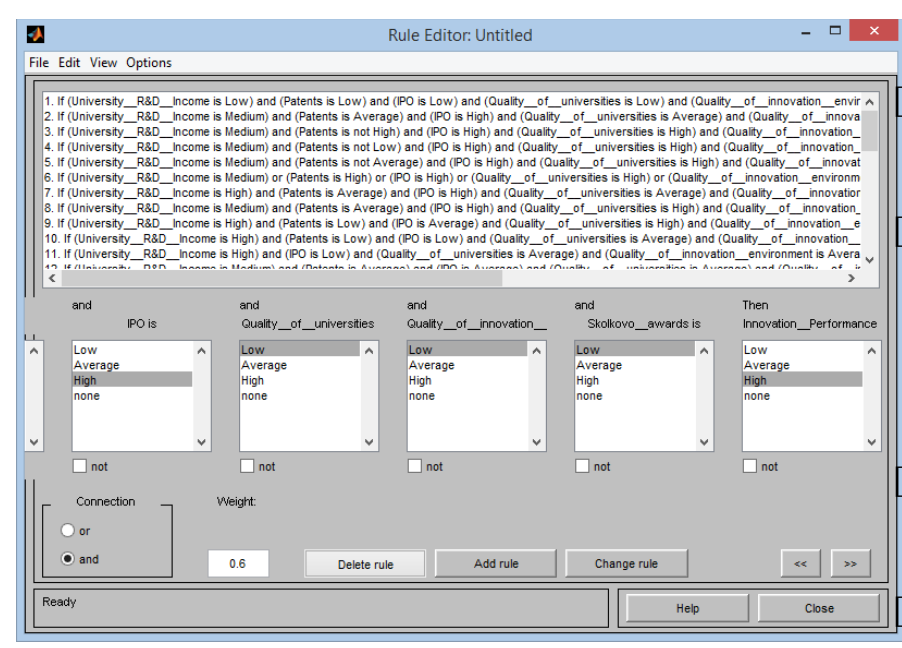

Fig. 5. The GUI of Rules Editor after setting the rule base.

\section{Conclusion}

The innovation project value measurement is very important for technologically advanced industrial enterprises development, because the innovations are the basic drive for country economic growth. However, there are many difficulties in measuring innovation project value. This paper suggests the model based on fuzzy logic, which helps to avoid some of these difficulties such as the usage qualitative and quantitative indicators separately in measuring innovation project value.

\section{References}

[1] V.I. Fomin, Social technologies in today's society, 2 (2012)

[2] Oslo Manual: Guidelines for Collecting and Interpreting Innovation Data (2005)

[3] Abby Joseph Cohen, Innovation and Economic Growth, The Goldman Sachs Group (2011)
[4] I.A. Brusakova, M.A. Kosukhina, Proc. conference on modern problems of applied informatics, 6-9 (2012)

[5] I.A. Brusakova, M.A. Kosukhina, Proc. Conference Proceeding of SCM on (2015)

[6] I.A. Brusakova, 2015 IV Forum Strategic Partnership of Universities and Enterprises of $\mathrm{Hi}$ Tech Branches, 77-79 (2015). DOI: 10.1109/IVForum.2015.7388260.

[7] A Guide to the Project Management Body of Knowledge (PMBOK Guide) (Project Management Institute Publ., 2013)

[8] I.A. Brusakova, M.A. Kossukhina, Proc. of the 10th Conference of Open Innovations Association FRUCT and the 2nd Finnish-Russian Mobile Linux Summit, 24-27 (2011)

[9] M.F. Kossukhina, H. Aminov, Proc. of the 12th Conference of Open Innovations Association FRUCT and e-Tourism seminar on, 37-40 (2012)

10] M.A. Kossukhina, Proc. of the 12th Conference of Open Innovations Association FRUCT and eTourism seminar on, 41-46 (2012)

11] I.A. Brusakova, V.I. Fomin, M.A. Kossukhina, S.N. Panin, Research of development trends of information management in modern conditions (Publishing house of Saint-Petersburg University. Univ of Management and Economics, St. Petersburg, 2014)

[12] H.J. Zimmermann, Fuzzy Set Theory and Its Applications (Kluwer Academic Publishers, Boston, MA, 1996)

13]A. Kaufmann, M.M. Gupta, Introduction to Fuzzy Arithmetic Theory and Application (Van Nostrand Reinhold, New York, 1991)

[14] T.A. Khudyakova, A.V. Shmidt, Proc. of The 26th International Business Information Management Association Conference, 1607-1611 (2015)

[15] T.A. Khudyakova, Proc. of the International Congress on Interdisciplinary Behavior and Social Science, 292-294 (2015)

[16]P. Romer, 8:1 Journal of Economic Perspectives, 322 (1994)

[17] J. Fagerberg, Journal of Economic Literature, 32, 1147-1175 (1994)

[18] C. Freeman, The Economics of Industrial Innovation (Penguin, London, 1974)

[19] C. Freeman, Cambridge Journal of Economics, 20, 1, 463 (1994)

[20]K. Beck, Extreme Programming Explained: Embrace Change (Addison-Wesley Professional Publ., 1999)

[21]D. Katalevsky, The Basics of Simulations and System Analysis in Management (Delo Publ., Moscow, 2015) 